\title{
Significant association between interleukin-10 gene polymorphisms and cervical cancer risk: a meta-analysis
}

\author{
Chong Guo ${ }^{1, *}$, Li Wen ${ }^{2, *}$, Ju-Kun Song ${ }^{3, *}$, Weng-Jing Zeng ${ }^{4}$, Chao Dan5, Yu-Ming \\ Niu ${ }^{1,6}$ and Ming Shen ${ }^{7}$ \\ ${ }^{1}$ Center for Evidence-Based Medicine and Clinical Research, Department of Gynecology and Obstetrics, Taihe Hospital, Hubei \\ University of Medicine, Shiyan 442000, China \\ ${ }^{2}$ Department of Dermatology, Suizhou Central Hospital, Hubei University of Medicine, Shiyan 442000, China \\ ${ }^{3}$ Department of Oral and Maxillary Surgery, Guizhou Provincial People's Hospital, Guiyang 550002, China \\ ${ }^{4}$ Department of Anesthesiology, Taihe Hospital, Hubei University of Medicine, Shiyan 442000, China \\ ${ }^{5}$ Department of Urinary Surgery, Taihe Hospital, Hubei University of Medicine, Shiyan 442000, China \\ ${ }^{6}$ Center for Evidence-Based Medicine and Clinical Research, Taihe Hospital, Hubei University of Medicine, Shiyan 442000, \\ China \\ 7 Jiangsu Key Laboratory of Oral Diseases, Department of Dental Implant, Affiliated Hospital of Stomatology, Nanjing Medical \\ University, Nanjing 210029, China \\ *These authors contributed equally to this work
}

Correspondence to: Yu-Ming Niu, email: niuyuming@yeah.net Ming Shen, email: mingshen85@yahoo.com

Keywords: interleukin-10; polymorphism; cervical cancer; meta-analysis

Received: July 12, $2017 \quad$ Accepted: December 04, $2017 \quad$ Published: January 12, 2018

Copyright: Guo et al. This is an open-access article distributed under the terms of the Creative Commons Attribution License 3.0 (CC BY $3.0)$, which permits unrestricted use, distribution, and reproduction in any medium, provided the original author and source are credited.

\section{ABSTRACT}

Previous studies have suggested that interleukin-10 (IL-10) polymorphisms may be associated with an increased risk of developing cervical cancer. However, the published results on this subject matter are controversial. The aim of this study was to conduct a meta-analysis of published reports to more precisely investigate the relationship between IL-10 polymorphisms and cervical cancer risk. Five online databases (PubMed, Embase, Web of SCI, CNKI and Wanfang) were searched, and seventeen articles with sufficient quantitative information were included in our metaanalysis. The odds ratios (ORs) and $95 \%$ confidence intervals (CIs) were calculated to assess the association between IL-10 polymorphisms and cervical cancer risk. Publication bias, sensitivity and cumulative analyses were also performed to support our findings. Overall, there was a significant association between the IL-10 -1082A > G polymorphism and cervical cancer risk observed in the total population (G vs. A: OR = $1.60,95 \% \mathrm{CI}=1.12-2.29, P=0.01, I^{2}=92.3 \%$; $A G$ vs. $A A: O R=1.34,95 \% C I=1.04-$ $1.74, P=0.03, I^{2}=65.9 \% ; A G+G G$ vs. $A A: O R=1.58,95 \% C I=1.11-2.25, P=0.01$, $I^{2}=84.4 \%$ ), and the same results were obtained in the subgroup analysis. Moreover, the IL-10-819 $\mathrm{T}>\mathrm{C}$ polymorphism exhibited a significant, protective effect against cervical cancer. In summary, our meta-analysis suggests that IL-10 polymorphisms may play a variety of roles in regard to cervical cancer risk, especially in Asians.

\section{INTRODUCTION}

Cervical cancer is the second most common form of cancer diagnosed in women and the third leading cause of death from cancer. This accounts for approximately $8 \%$ of total cancer cases and cancer deaths in women [1].
In 2012 , there were an estimated 527,600 new cervical cancer cases and 265,700 deaths from cervical cancer worldwide, mostly affecting developing countries [1]. Cervical cancer affects the cervix and encompasses squamous cell carcinomas (90\%), adenocarcinoma (10\%), and other subtypes $[2,3]$. Currently, a combination of 
surgery, radiotherapy and chemotherapy is still the most effective form of treatment for cervical cancer [4-6]. However, any form of treatment inevitably implies severe trauma to the patient, as well as an economic burden and mental stress [7-9]. A variety of risk factors, such as chronic inflammation, unhealthy living conditions, and human papillomavirus (HPV) infections have been proven to increase the risk of cervical tumorigenesis [10 13]. However, although numerous epidemiological and molecular biology-related studies have been conducted, the precise effects of these factors on the process of tumorigenesis process are still poorly understood.

In the last decade, numerous studies have suggested that certain cytokines may play critical roles in the processes of inflammatory cell infiltration and malignant cell transformation $[14,15]$. Interleukin-10 (IL-10) is a multifunctional cytokine that is mainly secreted by $\mathrm{T}$ helper type 2 cells (Th2 cells), monocytes/macrophages, keratinocytes and tumor cells as well, as well as human helpertype 2 cells (Th1 cells) [16, 17]. IL-10 exhibits complex biological effects, including the capacity to stimulate mast cells maturation and accelerate the proliferation and differentiation of B cells, restrain type 1 immune responses by inhibiting the production of cytokines such as IL-2, IFN-gamma, and other cytokines, decrease the IFN-gamma production by natural killer cells and interfere with macrophage activation [18]. IL-10 exhibits a dual role during cancer development, inducing both cancer-promoting (immunosuppressive) and cancerinhibiting (anti-angiogenic) effects [19].

Single nucleotide polymorphisms are one of the most common, heritable variations in the human genome, accounting for more than $90 \%$ of all variation [20]. The IL-10 gene is located on chromosome 1q3132 , which spans $4.8 \mathrm{~kb}$, and contains 5 exons and 4 introns that encode 178 amino acids [21]. To date, at least 50 polymorphic loci have been reported, such as $-2849,-2776,-2769$ and -2763 [22]. The three most common SNPs in the IL-10 promoter region that have been reported to significantly influence gene transcription and expression are $-1082 \mathrm{~A}>\mathrm{G}(\mathrm{rs} 1800870),-819 \mathrm{~T}>$ C (rs1800871) and -592C > A (rs1800872) [23]. Some molecular research has shown that these polymorphisms can influence and/or change the susceptibility of individuals to different forms of cancer, such as head and neck cancer, gastric cancer, leukemia, and others [24-26]. In 2001, Stanczuk et al. published the first case-control study examining the effects of the IL-10 $-1082 \mathrm{~A}>\mathrm{G}$ polymorphism on cervical cancer risk, and the results suggested that African women with an AG genotype were at an increased risk for cervical cancer [27]. To date, two meta-analyses have been conducted, examining previously published studies to elucidate the association between IL-10 polymorphisms and cervical cancer risk $[28,29]$. However, these meta-analyses have not been comprehensive and have not yielded consistent results.
Therefore, we conducted the present meta-analysis to provide a more precise and comprehensive assessment of the relationship between IL-10 polymorphisms and cervical cancer susceptibility. This meta-analysis was performed according to the guidelines of the Preferred Reporting Items for Systematic Reviews and MetaAnalyses (PRISMA) statement [30]. No ethical issues were implicated in this study because our data were based on previously published reports.

\section{RESULTS}

\section{Study characteristics}

Initially, 164 relevant articles were identified through our search strategy. The study selection procession is shown in Figure 1. After a comprehensive review, 86 articles were excluded because they were duplicate studies. After screening the title and the abstract, the full text of each article was analyzed. Eventually, 17 published articles (29 studies including polymorphisms at three different loci) involving 4,037 patients and 3,249 controls were included in this meta-analysis [27, 31-46]. Thirteen studies focused on the relationship between the $-1082 \mathrm{~A}>\mathrm{G}$ polymorphism and cervical cancer risk [27, 31-42], six studies focused on the relationship between the $-819 \mathrm{~T}>\mathrm{C}$ polymorphism and cervical cancer risk [31, $38-40,42,43]$, and ten studies focused on the relationship between the $-592 \mathrm{C}>\mathrm{A}$ polymorphism and cervical cancer risk [31, 33, 35, 38-40, 42, 44-46]. There were 10 articles that included 1,382 cases and 1,602 controls from Asian populations [31, 34-36, 38, 41-43, 45, 46], 5 articles that included 2,381 cases and 1,396 controls from Caucasian populations [33, 37, 39, 40, 44], and 2 articles that included 274 cases and 251 controls from African populations [27, 32]. Regarding the genotyping method, PCR was used in 13 studies (including ARMS-PCR, PCR-RFLP, PCR Pyrosequencing and Multiplex PCR techniques) [27, 31, 32, 34-38, 42-46], 4 studies reported using the Taqman method [33, 39-41]. The HWE values were calculated based on the genotype distributions of the groups. Some studies deviated from HWE for the IL$10-1082 \mathrm{~A}>\mathrm{G}$ polymorphism (four studies), $-819 \mathrm{~T}>\mathrm{C}$ polymorphism (two studies) and $-592 \mathrm{C}>\mathrm{A}$ polymorphism (one study). A summary of the characteristics of the included studies is shown in Table 1.

\section{Association between the IL-10 -1082A > G polymorphism and cervical cancer risk}

A total of thirteen relevant studies, consisting of 2,311 patients and 2,491 controls focused on the association between the IL-10 -1082A $>$ G polymorphism and cervical cancer risk. Overall, a significantly increased risk of cervical cancer was observed in three genetic models (G vs. A: $\mathrm{OR}=1.60,95 \% \mathrm{CI}=1.12-2.29, P=$ 
Table 1: Characteristics of case-control studies on IL-10 $-1082 \mathrm{~A}>\mathrm{G},-819 \mathrm{~T}>\mathrm{C}$ and $-592 \mathrm{C}>\mathrm{A}$ polymorphisms and cervical cancer risk

\begin{tabular}{|c|c|c|c|c|c|c|c|c|c|c|c|c|c|c|c|}
\hline \multirow[b]{3}{*}{$\begin{array}{l}\text { First au- } \\
\text { thor }\end{array}$} & \multirow[b]{3}{*}{ Year } & \multirow[b]{3}{*}{ Country } & \multirow[b]{3}{*}{$\begin{array}{c}\text { Racial de- } \\
\text { scent }\end{array}$} & \multirow[b]{3}{*}{$\begin{array}{c}\text { Source of } \\
\text { controls }\end{array}$} & \multirow[b]{3}{*}{ Case } & \multirow[b]{3}{*}{$\begin{array}{l}\text { Con- } \\
\text { trol }\end{array}$} & \multicolumn{6}{|c|}{ Genotype distribution } & \multirow[b]{3}{*}{$\begin{array}{c}P \text { for } \\
\text { HWE }\end{array}$} & \multirow[b]{3}{*}{$\begin{array}{l}\text { Genotyping } \\
\text { method }\end{array}$} & \multirow[b]{3}{*}{ NOS } \\
\hline & & & & & & & \multicolumn{3}{|c|}{ Case } & \multicolumn{3}{|c|}{ Control } & & & \\
\hline & & & & & & & $\mathbf{A A}$ & AG & GG & $\mathbf{A A}$ & AG & GG & & & \\
\hline Stanczuk & 2001 & Zimbabwe & African & HB & 77 & 69 & 45 & 31 & 1 & 58 & 11 & 0 & 0.472 & ARMS-PCR & 6 \\
\hline Roh & 2002 & Korea & Asian & HB & 144 & 179 & 144 & 0 & 0 & 179 & 0 & 0 & NA & PCR-RFLP & 4 \\
\hline Govan & 2003 & South Africa & African & HB & 197 & 182 & 88 & 80 & 29 & 76 & 65 & 41 & $<0.01$ & ARMS-PCR & 6 \\
\hline Zoodsma & 2005 & Netherlands & Caucasian & PB & 667 & 606 & 154 & 326 & 187 & 130 & 307 & 169 & 0.668 & Taqman & 9 \\
\hline Matsumoto & 2010 & Japanese & Asian & HB & 104 & 173 & 73 & 26 & 5 & 156 & 16 & 1 & 0.412 & ARMS-PCR & 7 \\
\hline $\mathrm{Yu}$ & 2011 & China & Asian & $\mathrm{HB}$ & 103 & 115 & 90 & 12 & 1 & 98 & 14 & 3 & 0.012 & ARMS-PCR & 6 \\
\hline Wang & 2011 & China & Asian & PB & 186 & 200 & 77 & 85 & 24 & 103 & 76 & 21 & 0.222 & PCR & 7 \\
\hline Barbisan & 2012 & Argentina & Caucasian & $\mathrm{HB}$ & 122 & 176 & 50 & 61 & 11 & 79 & 83 & 14 & 0.222 & $\begin{array}{l}\text { PCR Pyrose- } \\
\text { quencing }\end{array}$ & 6 \\
\hline Singhal & 2015 & India & Asian & $\mathrm{HB}$ & 208 & 250 & 32 & 76 & 100 & 100 & 107 & 43 & 0.125 & PCR-RFLP & 7 \\
\hline Zidi & 2015 & Tunisian & Caucasian & HB & 86 & 126 & 33 & 36 & 17 & 51 & 50 & 25 & 0.055 & TaqMan & 6 \\
\hline $\begin{array}{l}\text { Torres- } \\
\text { Poveda }\end{array}$ & 2015 & Mexico & Caucasian & $\mathrm{HB}$ & 200 & 200 & 121 & 70 & 9 & 110 & 78 & 12 & 0.708 & TaqMan & 8 \\
\hline Zeng & 2015 & China & Asian & HB & 52 & 50 & 5 & 7 & 40 & 24 & 22 & 0 & 0.033 & TaqMan & 5 \\
\hline \multirow[t]{2}{*}{ Bai } & 2016 & China & Asian & HB & 165 & 165 & 74 & 75 & 16 & 80 & 72 & 13 & 0.563 & PCR-RFLP & 7 \\
\hline & & & & & & & $\mathrm{TT}$ & $\mathrm{TC}$ & $\mathrm{CC}$ & $\mathrm{TT}$ & $\mathrm{TC}$ & $\mathrm{CC}$ & & & \\
\hline Roh & 2002 & Korea & Asian & HB & 144 & 179 & 77 & 56 & 11 & 87 & 77 & 15 & 0.724 & PCR-RFLP & 6 \\
\hline Singh & 2009 & India. & Asian & $\mathrm{HB}$ & 150 & 162 & 27 & 67 & 56 & 24 & 61 & 77 & 0.046 & PCR-RFLP. & 6 \\
\hline Singhal & 2015 & India & Asian & $\mathrm{HB}$ & 208 & 250 & 61 & 102 & 45 & 61 & 120 & 69 & 0.537 & PCR-RFLP & 7 \\
\hline Zidi & 2015 & Tunisian & Caucasian & HB & 86 & 126 & 9 & 32 & 45 & 4 & 66 & 56 & 0.003 & TaqMan & 5 \\
\hline $\begin{array}{l}\text { Torres- } \\
\text { Poveda }\end{array}$ & 2016 & Mexico & Caucasian & HB & 200 & 200 & 54 & 97 & 49 & 34 & 85 & 81 & 0.156 & TaqMan & 8 \\
\hline \multirow[t]{2}{*}{ Bai } & 2016 & China & Asian & $\mathrm{HB}$ & 165 & 165 & 44 & 75 & 45 & 28 & 73 & 64 & 0.362 & PCR-RFLP & 7 \\
\hline & & & & & & & $\mathrm{CC}$ & $\mathrm{CA}$ & $\mathrm{AA}$ & $\mathrm{CC}$ & $\mathrm{CA}$ & $\mathrm{AA}$ & & & \\
\hline Roh & 2002 & Korea & Asian & $\mathrm{HB}$ & 144 & 179 & 11 & 56 & 77 & 15 & 77 & 87 & 0.724 & PCR-RFLP & 6 \\
\hline Zoodsma & 2005 & Netherlands & Caucasian & PB & 667 & 606 & 393 & 231 & 30 & 405 & 175 & 26 & 0.206 & Taqman & 9 \\
\hline Ivansson & 2007 & Sweden & Caucasian & PB & 1306 & 288 & 736 & 464 & 82 & 162 & 112 & 14 & 0.334 & Multiplex PCR & 7 \\
\hline Xiong & 2010 & China & Asian & PB & 70 & 108 & 12 & 23 & 35 & 13 & 44 & 51 & 0.467 & PCR-RFLP & 8 \\
\hline $\mathrm{Yu}$ & 2011 & China & Asian & HB & 103 & 115 & 7 & 37 & 59 & 19 & 44 & 52 & 0.075 & ARMS-PCR & 7 \\
\hline Shekari & 2012 & India. & Asian & PB & 200 & 200 & 16 & 96 & 88 & 17 & 102 & 81 & 0.054 & PCR-RFLP & 7 \\
\hline Singhal & 2015 & India & Asian & HB & 208 & 250 & 85 & 94 & 29 & 60 & 123 & 67 & 0.810 & PCR-RFLP & 7 \\
\hline Zidi & 2015 & Tunisian & Caucasian & HB & 86 & 126 & 45 & 32 & 9 & 57 & 64 & 5 & 0.012 & TaqMan & 5 \\
\hline $\begin{array}{l}\text { Torres- } \\
\text { Poveda }\end{array}$ & 2016 & Mexico & Caucasian & HB & 200 & 200 & 44 & 98 & 58 & 85 & 85 & 30 & 0.255 & TaqMan & 8 \\
\hline Bai & 2016 & China & Asian & $\mathrm{HB}$ & 165 & 165 & 20 & 82 & 63 & 15 & 80 & 70 & 0.243 & PCR-RFLP & 7 \\
\hline
\end{tabular}

${ }^{\mathrm{a}} \mathrm{HWE}$ in control, PB: Population-base control, HB: Hospital-base control and/or healthy base control

$0.01, \mathrm{I}^{2}=92.3 \% ;$ AG vs. AA: OR $=1.34,95 \% \mathrm{CI}=1.04$ $1.74, P=0.03, \mathrm{I}^{2}=65.9 \% ; \mathrm{AG}+\mathrm{GG}$ vs. $\mathrm{AA}: \mathrm{OR}=1.58$, $95 \% \mathrm{CI}=1.11-2.25, P=0.02, \mathrm{I}^{2}=84.4 \%$ ) (Supplementary
Table 1, Figure $2 \mathrm{~A}$ for AG+GG vs. AA model). Subsequent subgroup analyses by ethnicity also revealed a similar risk in Asian populations in all five genetic models (G vs. A: 
$\mathrm{OR}=2.41,95 \% \mathrm{CI}=1.26-4.60, P=0.01, \mathrm{I}^{2}=93.3 \%$; AG vs. AA: $\mathrm{OR}=1.64,95 \% \mathrm{CI}=1.14-2.36, P=0.01, \mathrm{I}^{2}$ $=53.3 \%$; GG vs. AA: OR $=3.75,95 \% \mathrm{CI}=1.21-11.61$, $P=0.02, \mathrm{I}^{2}=85.2 \% ; \mathrm{AG}+\mathrm{GG}$ vs. $\mathrm{AA}: \mathrm{OR}=2.28,95 \%$ $\mathrm{CI}=1.27-4.10, P=0.01, \mathrm{I}^{2}=84.6 \%$; GG vs. AA+AG: $\mathrm{OR}=2.94,95 \% \mathrm{CI}=1.08-8.03, P=0.04, \mathrm{I}^{2}=83.7 \%$ ). Moreover, a significant risk of cervical cancer was also seen in all five genetic models for the HWE, the hospital control and the PCR genotyping groups (Supplementary Table 1). Heterogeneity was observed in all five genetic models. Meta-regression analyses were conducted, but the results failed to identify any factors contributing to the observed heterogeneity.

A cumulative analysis by publication date demonstrated that cancer risk increased gradually and became positive following the study conducted by Singhal et al. in 2012 were included (Figure 2B for AG+GG vs. AA model). A sensitivity analysis revealed that no single study qualitatively changed the pooled ORs, indicating that the results of this meta-analysis were stable (Figure $2 \mathrm{C}$ for $\mathrm{AG}+\mathrm{GG}$ vs. AA model).

Publication bias was assessed with Funnel plots. Plot asymmetry was observed only in the AG+GG vs. AA model, which was redressed in the subgroup analysis by ethnicity (Figure 2D for AG+GG vs. AA model). These results were further supported by Egger's tests (G vs. A: $P=0.12$; AG vs. AA: $P=0.06$; GG vs. AA: $P=0.34$; AG+GG vs. AA: $P=0.03$; GG vs. $\mathrm{AA}+\mathrm{AG}: P=0.46)$.

\section{Association between the IL-10 -819T > C polymorphism and cervical cancer risk}

Six studies involving 953 cases and 1,082 controls were included in this meta-analysis to assess the association between the IL-10 -819T > C polymorphism and cervical cancer risk. Interestingly, all genetic models indicated that they confer a protective effect against cervical cancer occurrence $(\mathrm{C}$ vs. $\mathrm{T}, \mathrm{OR}=0.74,95 \% \mathrm{CI}$ $=0.65-0.84, P<0.01, \mathrm{I}^{2}=23.8 \%$; TC vs. TT, OR $=0.76$, $95 \% \mathrm{CI}=0.61-0.95, \mathrm{P}=0.02, \mathrm{I}^{2}=2.6 \%$; CC vs. TT, OR $=0.53,95 \% \mathrm{CI}=0.41-0.70, P<0.01, \mathrm{I}^{2}=0 \%$; $\mathrm{TC}+\mathrm{CC}$ vs. TT, OR $=0.68,95 \% \mathrm{CI}=0.55-0.84, P<0.01, \mathrm{I}^{2}=$ $0 \%$; CC vs. TT+TC, OR $=0.71,95 \% \mathrm{CI}=0.54-0.95, \mathrm{P}=$ $0.02, \mathrm{I}^{2}=48.7 \%$ ) (Supplementary Table 1, Figure 3A for TC+CC vs. TT model). Furthermore, subgroup analyses based on HWE status, the ethnicity, the control design and the genotyping method all indicated the same protective effect (Supplementary Table 1).

The cumulative analysis also indicated some change only in the recessive model (Figure $3 \mathrm{~B}$ for $\mathrm{TC}+\mathrm{CC}$ vs. TT model). A sensitivity analysis was conducted, and no conspicuous change in the pooled ORs was detected except in the recessive model (Figure $3 \mathrm{C}$ for $\mathrm{TC}+\mathrm{CC}$ vs. TT model). Moreover, no publication bias was observed, indicating that the results were statistically robust $(\mathrm{C}$ vs. T: $P=0.23$; TC vs. TT: $P=0.06$; $C$ vs. TT: $P=$
0.96 ; TC+CC vs. TT: $P=0.11 ; \mathrm{CC}$ vs. TT+TC: $P=0.26)$

(Figure $3 \mathrm{D}$ for $\mathrm{TC}+\mathrm{CC}$ vs. TT model).

\section{Association between the IL-10 -592C > A polymorphism and cervical cancer risk}

For the IL-10 -592C > A polymorphism, ten studies consisting of 3,149 cases and 2,237 controls were pooled in the meta-analysis to assess whether this IL-10 -592C $>$ A polymorphism was associated with cervical cancer risk. Overall, no significant association was observed in any of the five models (Supplementary Table 1; Figure 4A for $\mathrm{CA}+\mathrm{AA}$ vs. $\mathrm{CC}$ model). Only two genetic models (for AA vs. $\mathrm{CC}$, $\mathrm{OR}=1.86,95 \% \mathrm{CI}=1.02-$ $3.39, P=0.04, \mathrm{I}^{2}=69.6 \%$; for AA vs. $\mathrm{CC}+\mathrm{CA}, \mathrm{OR}=$ $1.62,95 \% \mathrm{CI}=1.06-2.49, P=0.03, \mathrm{I}^{2}=46.6 \%$ ) revealed an increased risk for cervical cancer in the Caucasian population group. Additional subgroup analyses were conducted based on HWE status, the control design and the genotyping method, but no significant associations were observed. The pooled ORs did not exhibit any changes following sensitivity or cumulative analyses, and no publication bias was observed (Figure 4B and $4 \mathrm{C}$ for $\mathrm{CA}+\mathrm{AA}$ vs. $\mathrm{CC}$ model). Moreover, no publication bias was observed (A vs. $\mathrm{C}: \mathrm{P}=0.96$; $\mathrm{CA}$ vs. $\mathrm{CC}: \mathrm{P}=$ 0.63 ; AA vs. $\mathrm{CC}: P=0.58$; $\mathrm{CA}+\mathrm{AA}$ vs. $\mathrm{CC}: P=0.82$; $\mathrm{AA}$ vs. $\mathrm{CC}+\mathrm{CA}: P=0.34$ ) (Figure $4 \mathrm{D}$ for $\mathrm{CA}+\mathrm{AA}$ vs. $\mathrm{CC}$ model).

\section{DISCUSSION}

Genetic factors are now known to be important variables affecting the susceptibility of patients to various diseases and have been paid an increasing amount of attention [47, 48]. Inflammatory and immune cytokines play important roles during the process of tumorigenesis transition from normal epithelium to malignant tumors, and these cytokines can promote this process by inducing angiogenesis, compensatory cell proliferation, DNA damage, or the accumulation of gene mutations [49]. Gene mutations, especially polymorphisms in the promoter region, can affect the process of gene transcription, resulting in abnormal expression of the corresponding mRNAs and dysfunction of the expressed proteins. These mutations can also influence the susceptibility of individuals to cancer $[50,51]$.

Since 2001, a large number of molecular epidemiological case-control studies have been conducted to explore the association between IL-10 polymorphisms and cervical cancer risk, but the results have been inconsistent. In terms of the IL-10 -1082A > $\mathrm{G}$ polymorphism, Singhal et al. reported a case-control study in an Indian population, the AG and GG genotypes may significantly increase the risk of cervical cancer development compared with the AA genotype (AG vs. AA: $\mathrm{OR}=2.2,95 \% \mathrm{CI}=1.35-3.64 ; \mathrm{GG}$ vs. AA: OR 
Table 2: Scale for quality evaluation

Criteria

Score

Representativeness of cases

Consecutive/randomly selected cases with clearly defined sampling frame

Not consecutive/randomly selected case or without clearly defined sampling frame

Not described

Source of controls

Population-base control

Hospital-base control and/or healthy base control

Not described

Hardy-Weinberg equilibrium in controls

Hardy-Weinberg equilibrium

Hardy-Weinberg disequilibrium

Not available

Genotyping examination

Genotyping done under "blinded" condition and repeated again

Genotyping done under "blinded" condition or repeated again

Unblinded done or not mentioned and unrepeated

Association assessment

Assess association between genotypes and cancer with appropriate statistics and adjustment for

Assess association between genotypes and cancer with appropriate statistics and without

$=7.26,95 \% \mathrm{CI}=4.2-12.4$ ) [38]. A similarly increased risk was also observed in other studies. In contrast, other studies reported a negative association between the IL10-1082A $>$ G polymorphism and cervical cancer risk. For $-819 \mathrm{~T}>\mathrm{C}$ and $-592 \mathrm{C}>\mathrm{A}$ polymorphisms, there is still controversy regarding the relationship between these two polymorphisms and cervical cancer susceptibility.

In 2013, $\mathrm{Ni}$ et al. published the first metaanalysis examining the association between IL-10 gene polymorphisms and cervical cancer risk. Their metaanalysis included eight studies comprising 1,498 cases and 1,608 controls for the IL-10 - $1082 \mathrm{~A}>\mathrm{G}$ polymorphism, as well as five studies involving 2,396 cases and 1,388 controls for the IL-10 -592C $>$ A polymorphism [28]. The researchers found that the IL-10 $-592 \mathrm{C}>$ A polymorphism was associated with an increased risk of cervical cancer development. No significant association was found for the IL-10 -1082A > G polymorphism [28]. In 2014, Zhang et al. conducted another meta-analysis to evaluate the association between the IL-10 -1082A $>$ G polymorphism and cervical cancer risk. This study included eight case-control studies comprising 1,983 cases and 1,618 controls; they also reported no association between this polymorphism and cervical cancer susceptibility [29]. Moreover, the association between the IL-10-819T > C polymorphism and cervical cancer risk was also explored in the subgroup analysis by $\mathrm{Yu}$ et al. in 2013. This analysis only included three case-control studies, with 1,895 subjects, and indicated that there was a positive association with cervical cancer in some genetic models [52].

Compared with the previous meta-analyses, our meta-analysis relied on a more scientifically sound retrieval strategy and included more research studies (seventeen publications involving 7,286 individuals) to accurately assess the associations between the IL-10 $-1082 \mathrm{~A}>\mathrm{G},-819 \mathrm{~T}>\mathrm{C}$ and $-592 \mathrm{C}>\mathrm{A}$ polymorphisms and cervical cancer risk. Our results suggest that the IL10-1082A > G polymorphism may be associated with an increased risk of cervical cancer development. In contrast, the IL-10-819T > C polymorphism may have a protective effect against cervical cancer development, especially in Asian populations. In the stratified analysis, the heterogeneity between the included IL-10-1082A $>$ G polymorphism studies was moderately, and successfully reduced by the subgroup analysis based on ethnicity. This suggests that ethnic diversity maybe a potential heterogeneity factor. Moreover, after conducting the sensitivity and publication bias analyses, no significant alterations or bias were observed for any of the three polymorphisms, presenting the stability of the results of our meta-analysis. 
To our knowledge, this is the first meta-analysis to examine the association between IL-10 polymorphisms and cervical cancer risk, including the three most common polymorphic loci (IL-10 -1082A $>$ G, -819T $>\mathrm{C}$ and $-592 \mathrm{C}>\mathrm{A})$. However, there are some limitations of this study that should be addressed. First, only seventeen publications were included in our meta-analysis. The limited number of studies and sample size for each polymorphic locus may reduce the reliability of the results and affect the assessment of associations between these IL-10 polymorphisms and cervical cancer susceptibility. Second, additional risk factors, such as smoking, drinking, and HPV infection, were not considered. The interactions between genetic and environmental factors and cancer development could not be evaluated in our analysis. Third, the association between the IL-10 -1082A $>$ G, $-819 \mathrm{~T}>\mathrm{C}$ and $-592 \mathrm{C}>\mathrm{A}$ polymorphisms and cervical cancer risk were analyzed separately, and the influence of the haplotype and gene-gene interactions was not analyzed due to an insufficient amount of data. Fourth, the heterogeneity that exists between the IL-10-1082A $>\mathrm{G}$ polymorphism studies could influence the current results and distort the conclusions. In this meta-regression analysis, we could not find the source of the heterogeneity, although it could be reduced in the subgroup analysis.
In summary, our meta-analysis suggests that the IL-10-1082A > G and -819T > C polymorphisms are associated with cervical cancer susceptibility, but with contradictory effects. In contrast, no significant association was found between the IL-10-592C > A polymorphism and cervical cancer susceptibility.

\section{MATERIALS AND METHODS}

\section{Literature search strategy}

A comprehensive literature search (up until June 1 ${ }^{\text {st }}$, 2017) was independently performed by two of the authors, without restrictions on the geographic region or language of publications from the following online databases: PubMed, Embase, Science Citation Index (SCI), CNKI and Wanfang. References appearing in relevant reports and recent reviews were all screened to identify potential articles of interest. The search terms"Interleukin-10", "polymorphism" AND "cervical cancer", and the following search strategy were used (in PubMed, for example): \#1 Interleukin-10, \#2 IL-10, \#3 rs1800870, \#4 rs1800871, \#5 rs1800872, \#6 \#1 OR \#2 OR \#3 OR \#4 OR \#5, \#7 polymorphism, \#8 variant, \#9 mutation, \#10 \#7 OR \#8 OR \#9, \#11 cervical cancer, \#12 cervical tumor, \#13

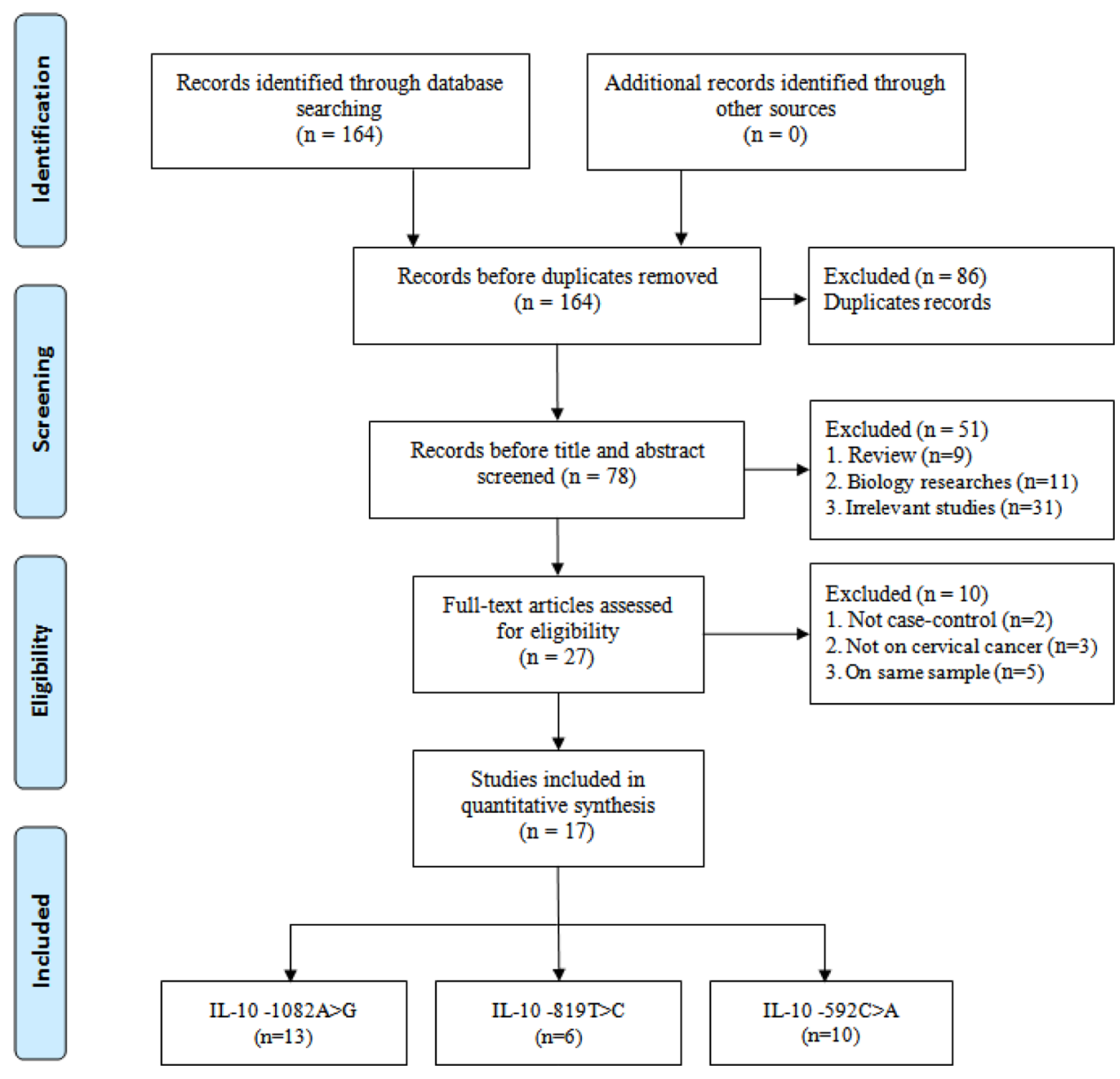

Figure 1: Flow diagram of the study selection process. 

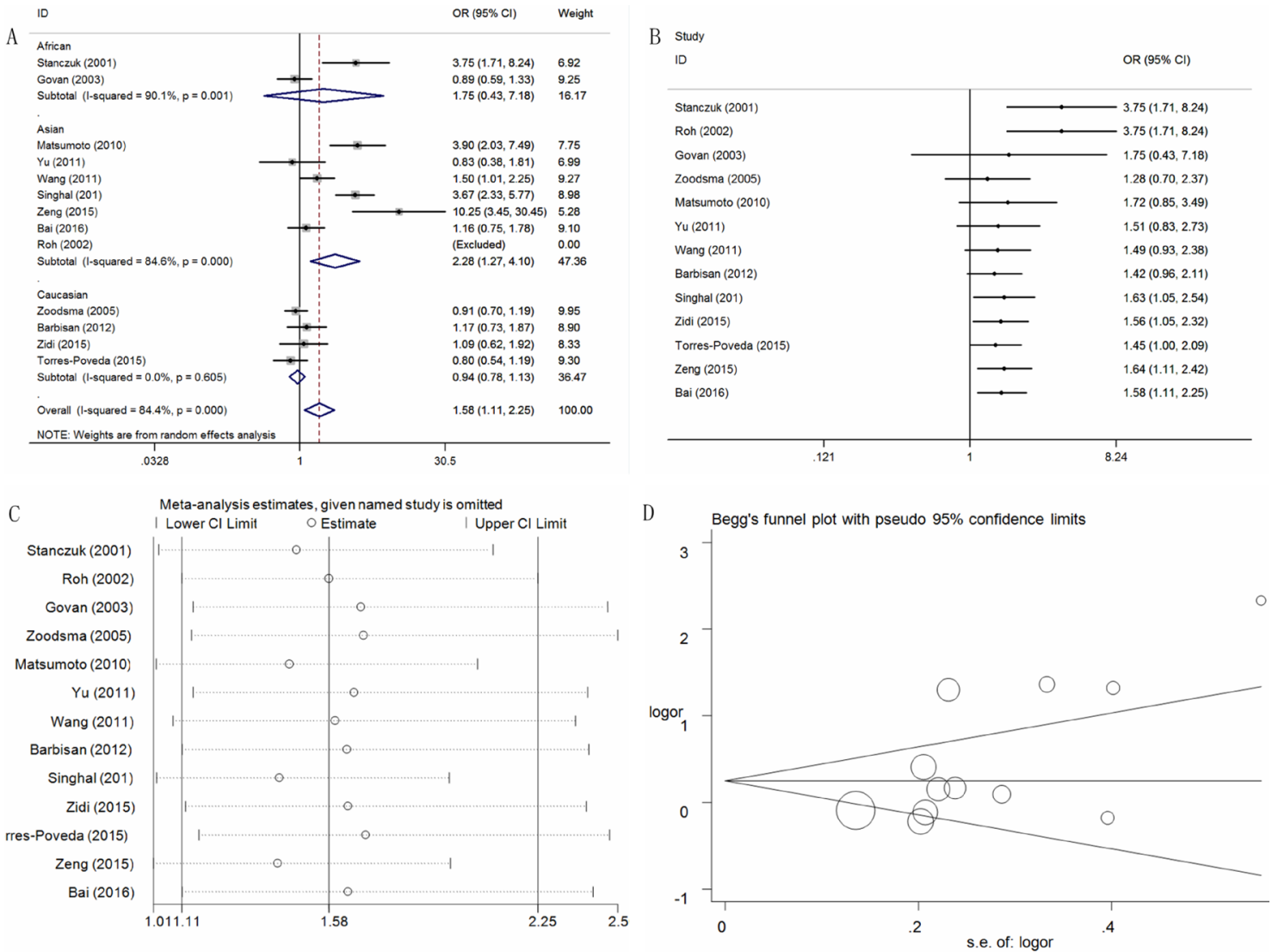

Figure 2: Statistical analysis of the association between the IL-10 -1082A $>$ G polymorphism and cervical cancer risk in the AG+GG vs. AA model. (A) ORs and 95\% CIs; (B) cumulative analysis; (C) sensitivity analysis; (D) publication bias.
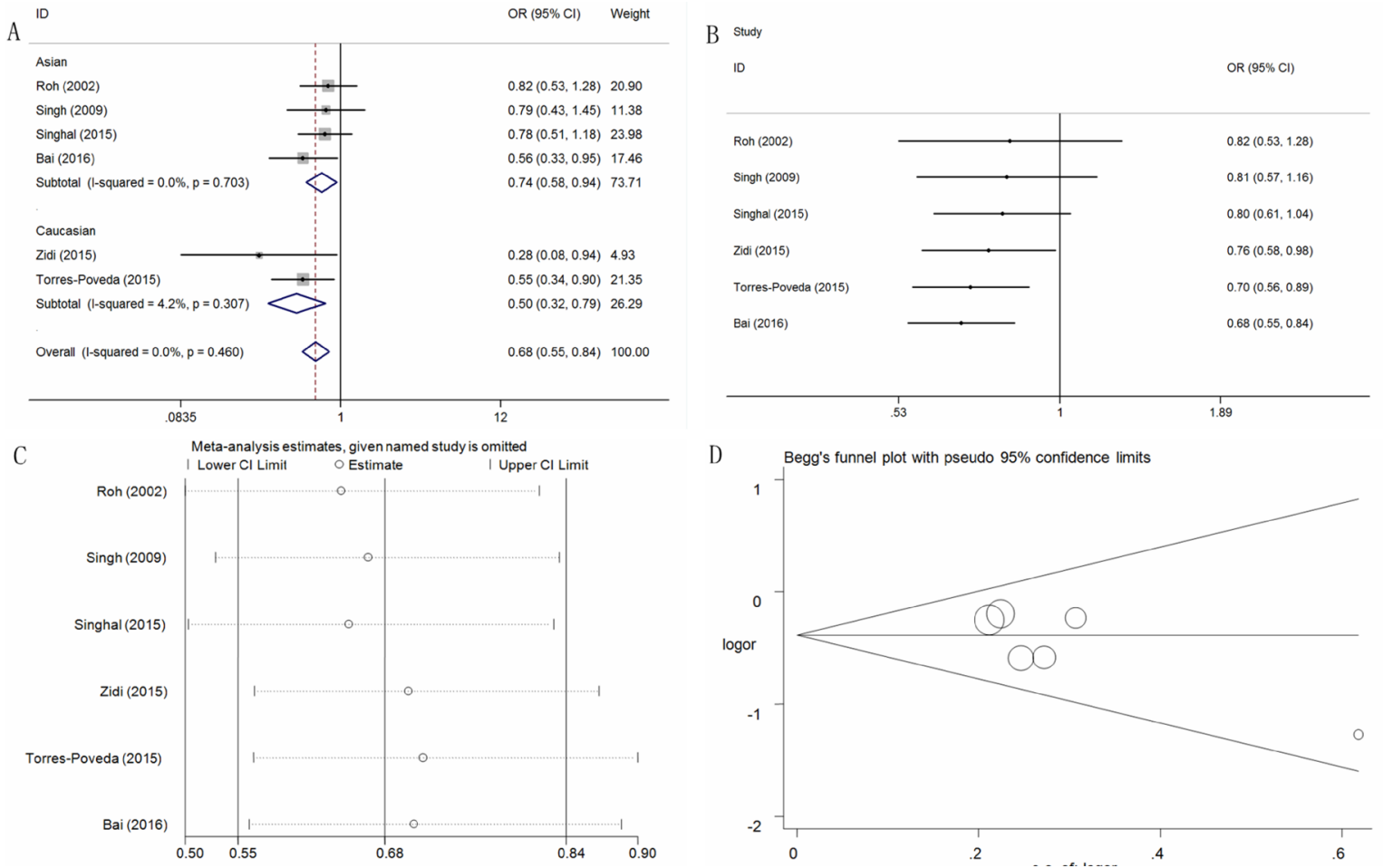

Figure 3: Statistical analysis of the association between the IL-10 -819T $>C$ polymorphism and cervical cancer risk in the TC+CC vs. TT model. (A) ORs and 95\% CIs; (B) cumulative analysis; (C) sensitivity analysis; (D) publication bias. 
cervical neoplasm, \#14 \#11 OR \#12 OR \#13, \#15 \#6 AND \#10 AND \#14.

\section{Eligibility criteria}

To be included in this study, publications had to meet the following inclusion criteria: 1) the study design had to be a case-control study (including retrospective or prospective studies); 2) the focus of the study had to be on IL-10 promoter polymorphisms (-1082A $>\mathrm{G},-819 \mathrm{~T}$ $>\mathrm{C}$ and $-592 \mathrm{C}>\mathrm{A})$; 3) the case group had to include women with cervical cancer and the control group had to consist of women without cervical cancer; 4) the reports had to include sufficient information on the frequency distribution of different genotypes in order to calculate the odds ratios (ORs) and 95\% confidence intervals (CIs); and 5) in the case that there were duplicate studies, we included the most recent or those with the largest samples sizes.

\section{Data extraction and quality evaluation}

Two investigators (Guo and Wen), independently extracted the following information from all of the included studies: first author, year of publication, study country or region where the study was performed, ethnicity (Asian, Caucasian or African), the source of the controls, the sample sizes of patients and controls, data on the frequency distribution of different genotypes, the Hardy-Weinberg equilibrium (HWE) for the controls, and the genotyping method. In addition, the modified Newcastle-Ottawa scale (NOS) was employed by the first two authors in order to evaluate the quality of the included studies [53]. The scores ranged from 0 points (worst) to 10 points (best). Studies with a score of 7 or higher were classified as high quality (Table 2 ).

\section{Statistical analysis}

ORs with $95 \%$ CIs were calculated to assess the strength of the association between the IL-10 -1082A $>\mathrm{G},-819 \mathrm{~T}>\mathrm{C}$ and $-592 \mathrm{C}>\mathrm{A}$ polymorphisms and cervical cancer susceptibility. For the IL-10 -1082A $>$ G polymorphism, the five following genetic models were used: allele contrast model ( $\mathrm{G}$ vs. A), co-dominant models (AG vs. AA and GG vs. AA), dominant model ( $\mathrm{AG}+\mathrm{GG}$ vs. AA), and recessive model (GG vs. AA+AG). The same genetic models were also used to assess the IL-10 -819T > $\mathrm{C}$ and $-592 \mathrm{C}>\mathrm{A}$ polymorphisms. Subgroup analyses were performed according to HWE status, ethnicity difference,
A

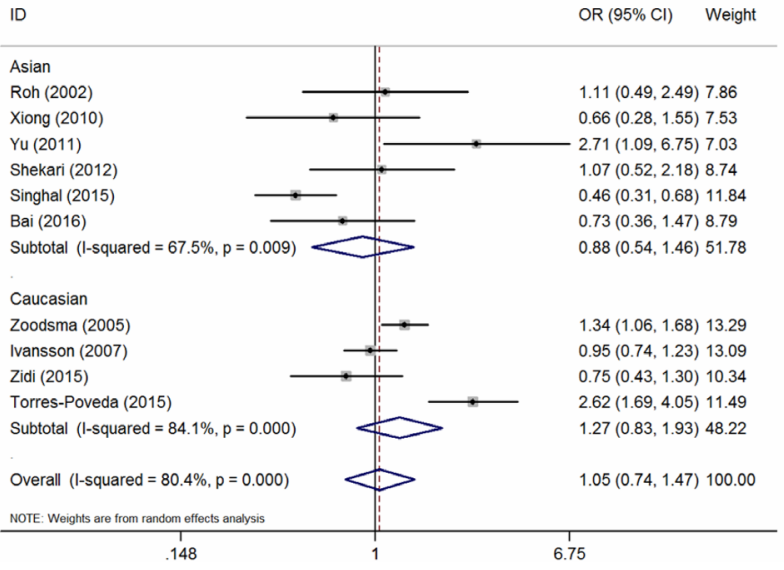

C

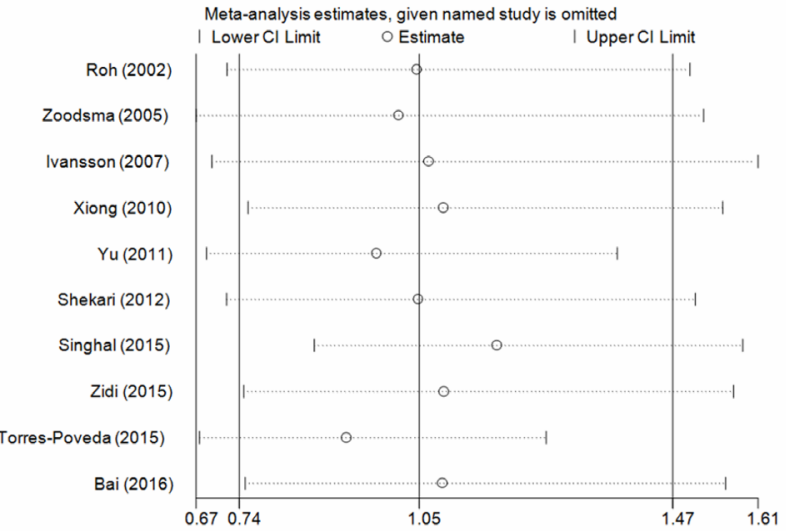

B stud

ID $\quad$ OR (95\% CI)

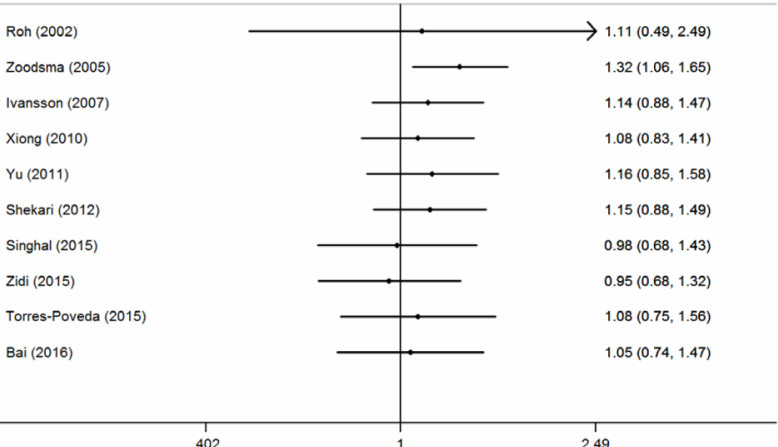

D

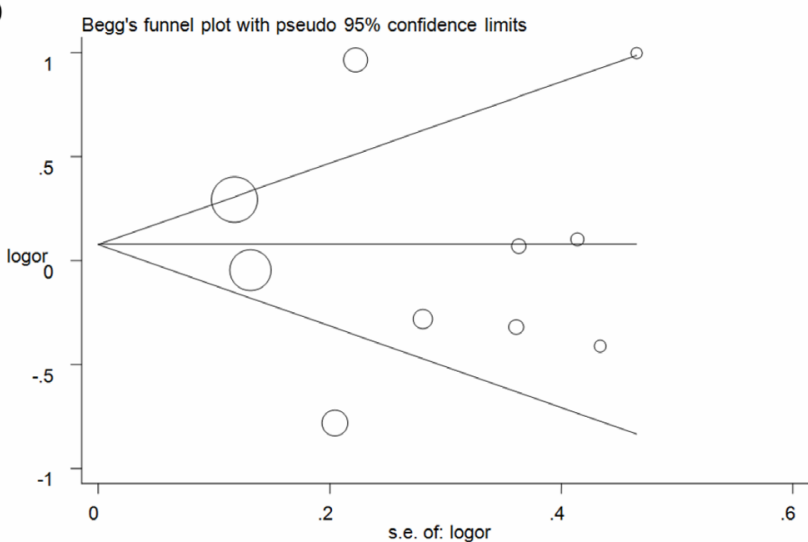

Figure 4: Statistical analysis of the association between the IL-10 -592C $>$ A polymorphism and cervical cancer risk in the CA+AA vs. CC model. (A) ORs and 95\% CIs; (B) cumulative analysis; (C) sensitivity analysis; (D) publication bias. 
control designs, and genotyping methods. Heterogeneity between studies was determined via a Cochran's $Q$ test and the $\mathrm{I}^{2}$ statistic [54]. A fixed-effect model (the Mantel-Haenszel method) was used when the $P$-value was more than 0.10 and the $\mathrm{I}^{2}$ was less than $40 \%$ [55]. Otherwise, a random-effects model (the DerSimonian and Laird method) was adopted [56]. Meta-regression analyses were conducted to explore the potential factors that contribute to heterogeneity. Furthermore, cumulative meta-analyses were conducted to observe whether the trend changed with the addition of studies. Sensitivity analyses were also conducted to evaluate the robustness of our results. Egger's linear regression and Begg's funnel plots were used to examine any potential publication bias $[57,58]$. All statistical calculations were performed with STATA version 14.0 (Stata Corporation, College Station, TX, USA). A two-sided $P$ value $<0.05$ was considered significant.

\section{CONFLICTS OF INTEREST}

The authors declare no competing financial interests.

\section{FUNDING}

This study was supported by the Foundations of the Science and Technology Department of Hubei Province (No. 2016CFB567, 2014CFB364) and Hubei Province health and family planning scientific research project (No. WJ2017F069, WJ2015Q041) and Bureau of Science and Technology of Shiyan City (17K67). The funders had no roles in study design, data collection and analysis, decision to publish, or preparation of the manuscript.

\section{REFERENCES}

1. Torre LA, Bray F, Siegel RL, Ferlay J, Lortet-Tieulent J, Jemal A. Global cancer statistics, 2012. CA Cancer J Clin. 2015; 65:87-108.

2. Smith HO, Tiffany MF, Qualls CR, Key CR. The rising incidence of adenocarcinoma relative to squamous cell carcinoma of the uterine cervix in the United States--a 24-year population-based study. Gynecol Oncol. 2000; 78:97-105.

3. Wang SS, Sherman ME, Hildesheim A, Lacey JV Jr, Devesa S. Cervical adenocarcinoma and squamous cell carcinoma incidence trends among white women and black women in the United States for 1976-2000. Cancer. 2004; 100:1035-1044.

4. Nedovic J, Protrka Z, Ninkovic S, Mitrovic S, Vojinovic R, Glisic J, Markovic-Filipovic B, Milosevic B, Peulic M, Cvetkovic A. Cisplatin monotherapy with concurrent radiotherapy versus combination of cisplatin and 5-fluorouracil chemotherapy with concurrent radiotherapy in patients with locoregionally advanced cervical carcinoma. J BUON. 2012; 17:740-745.
5. Rose PG, Bundy BN, Watkins EB, Thigpen JT, Deppe G, Maiman MA, Clarke-Pearson DL, Insalaco S. Concurrent cisplatin-based radiotherapy and chemotherapy for locally advanced cervical cancer. N Engl J Med. 1999; 340:1144-1153.

6. Chen X, Zou H, Li H, Lin R, Su M, Zhang W, Zhou Y, Zhang P, Hou M, Deng X, Zou C. Weekly Versus Triweekly Cisplatin-Based Chemotherapy Concurrent With Radiotherapy in the Treatment of Cervical Cancer: A Meta-Analysis. Int J Gynecol Cancer. 2017; 27:344-349.

7. Eberth JM, Prarelkar P, Nguyen H, Sun C, Irvin-Vidrine J, Elting LS. The Human and Economic Burden of Cervical Cancer in Texas. Tex Public Health J. 2013; 65:51-55.

8. Herzog TJ, Wright JD. The impact of cervical cancer on quality of life--the components and means for management. Gynecol Oncol. 2007; 107:572-577.

9. Distefano M, Riccardi S, Capelli G, Costantini B, Petrillo M, Ricci C, Scambia G, Ferrandina G. Quality of life and psychological distress in locally advanced cervical cancer patients administered pre-operative chemoradiotherapy. Gynecol Oncol. 2008; 111:144-150.

10. Muñoz N, Bosch FX, de Sanjosé S, Herrero R, Castellsagué $\mathrm{X}$, Shah KV, Snijders PJ, Meijer CJ, and International Agency for Research on Cancer Multicenter Cervical Cancer Study Group. Epidemiologic classification of human papillomavirus types associated with cervical cancer. $\mathrm{N}$ Engl J Med. 2003; 348:518-527.

11. Bayo S, Bosch FX, de Sanjose S, Munoz N, Combita AL, Coursaget P, Diaz M, Dolo A, van den Brule AJ, Meijer CJ. Risk factors of invasive cervical cancer in Mali. Int $\mathbf{J}$ Epidemiol. 2002; 31:202-209.

12. Fernandes JV, DE Medeiros Fernandes TA, DE Azevedo JC, Cobucci RN, DE Carvalho MG, Andrade VS, DE Araújo JM. Link between chronic inflammation and human papillomavirus-induced carcinogenesis (Review). Oncol Lett. 2015; 9:1015-26.

13. Park B, Kim SI, Seo SS, Kang S, Park SY, Lim MC. Health Behaviors and Associated Sociodemographic Factors in Cervical Cancer Survivors Compared with Matched NonCancer Controls. PLoS One. 2016; 11:e0160682.

14. Lee CH, Chang JS, Syu SH, Wong TS, Chan JY, Tang YC, Yang ZP, Yang WC, Chen CT, Lu SC, Tang PH, Yang TC, Chu PY, et al. IL-1beta promotes malignant transformation and tumor aggressiveness in oral cancer. J Cell Physiol. $2015 ; 230: 875-884$.

15. Liu H, Antony S, Roy K, Juhasz A, Wu Y, Lu J, Meitzler JL, Jiang G, Polley E, Doroshow JH. Interleukin-4 and interleukin-13 increase NADPH oxidase 1-related proliferation of human colon cancer cells. Oncotarget. 2017; 8:38113-35. https://doi.org/10.18632/oncotarget.17494.

16. Moore KW, de Waal Malefyt R, Coffman RL, O'Garra A. Interleukin-10 and the interleukin-10 receptor. Annu Rev Immunol. 2001; 19:683-765. 
17. Cecil DL, Holt GE, Park KH, Gad E, Rastetter L, Childs J, Higgins D, Disis ML. Elimination of IL-10-inducing T-helper epitopes from an IGFBP-2 vaccine ensures potent antitumor activity. Cancer Res. 2014; 74:2710-2718.

18. Sun L, Cornell TT, LeVine A, Berlin AA, HinkovskaGalcheva V, Fleszar AJ, Lukacs NW, Shanley TP. Dual role of interleukin-10 in the regulation of respiratory syncitial virus (RSV)-induced lung inflammation. Clin Exp Immunol. 2013; 172:263-279.

19. Howell WM, Rose-Zerilli MJ. Cytokine gene polymorphisms, cancer susceptibility, and prognosis. J Nutr. 2007; 137:194S-199S.

20. Collins FS, Brooks LD, Chakravarti A. A DNA polymorphism discovery resource for research on human genetic variation. Genome Res. 1998; 8:1229-1231.

21. Eskdale J, Kube D, Tesch H, Gallagher G. Mapping of the human IL10 gene and further characterization of the 5' flanking sequence. Immunogenetics. 1997; 46:120-128.

22. Willeke P, Gaubitz M, Schotte H, Becker H, Domschke $\mathrm{W}$, Schluter B. The role of interleukin-10 promoter polymorphisms in primary Sjogren's syndrome. Scand J Rheumatol. 2008; 37:293-299.

23. Ouma C, Davenport GC, Were T, Otieno MF, Hittner JB, Vulule JM, Martinson J, Ong'echa JM, Ferrell RE, Perkins DJ. Haplotypes of IL-10 promoter variants are associated with susceptibility to severe malarial anemia and functional changes in IL-10 production. Hum Genet. 2008; 124:515-524.

24. Niu YM, Du XY, Cai HX, Zhang C, Yuan RX, Zeng XT, Luo J. Increased risks between Interleukin-10 gene polymorphisms and haplotype and head and neck cancer: a meta-analysis. Sci Rep. 2015; 5:17149.

25. de Oliveira JG, Rossi AF, Nizato DM, Cadamuro AC, Jorge YC, Valsechi MC, Venancio LP, Rahal P, Pavarino EC, Goloni-Bertollo EM, Silva AE. Influence of functional polymorphisms in TNF-alpha, IL-8, and IL-10 cytokine genes on mRNA expression levels and risk of gastric cancer. Tumour Biol. 2015; 36:9159-9170.

26. Hiroki CH, Amarante MK, Petenuci DL, Sakaguchi AY, Trigo FC, Watanabe MA, de Oliveira CE. IL-10 gene polymorphism and influence of chemotherapy on cytokine plasma levels in childhood acute lymphoblastic leukemia patients: IL-10 polymorphism and plasma levels in leukemia patients. Blood Cells Mol Dis. 2015; 55:168-172.

27. Stanczuk GA, Sibanda EN, Perrey C, Chirara M, Pravica V, Hutchinson IV, Tswana SA. Cancer of the uterine cervix may be significantly associated with a gene polymorphism coding for increased IL-10 production. Int J Cancer. 2001; 94:792-794.

28. Ni J, Ye Y, Teng F, Wu Q. Interleukin 10 polymorphisms and cervical cancer risk: a meta-analysis. Int J Gynecol Cancer. 2013; 23:126-133.

29. Zhang S, Kong YL, Li YL, Yin YW. Interleukin-10 gene -1082 G/A polymorphism in cervical cancer and cervical intraepithelial neoplasia: meta-analysis. J Int Med Res. 2014; 42:1193-1201.
30. Moher D, Liberati A, Tetzlaff J, Altman DG, and PRISMA Group. Preferred reporting items for systematic reviews and meta-analyses: the PRISMA statement. J Clin Epidemiol. 2009; 62:1006-1012.

31. Roh JW, Kim MH, Seo SS, Kim SH, Kim JW, Park NH, Song YS, Park SY, Kang SB, Lee HP. Interleukin-10 promoter polymorphisms and cervical cancer risk in Korean women. Cancer Lett. 2002; 184:57-63.

32. Govan VA, Carrara HR, Sachs JA, Hoffman M, Stanczuk GA, Williamson AL. Ethnic differences in allelic distribution of IFN-g in South African women but no link with cervical cancer. J Carcinog. 2003; 2:3.

33. Zoodsma M, Nolte IM, Schipper M, Oosterom E, van der Steege G, de Vries EG, Te Meerman GJ, van der Zee AG. Interleukin-10 and Fas polymorphisms and susceptibility for (pre)neoplastic cervical disease. Int J Gynecol Cancer. 2005; 15:S282-90.

34. Matsumoto K, Oki A, Satoh T, Okada S, Minaguchi T, Onuki M, Ochi H, Nakao S, Sakurai M, Abe A, Hamada H, Yoshikawa H. Interleukin-10 -1082 gene polymorphism and susceptibility to cervical cancer among Japanese women. Jpn J Clin Oncol. 2010; 40:1113-1116.

35. Yu XM, Ma D, Wu SQ, Guan WJ, Feng GM, Gao HX, Li O. Relationship between polymorphisms of IL-10 gene and cervical cancer. Zhongguo Yiyuan Ganranxue Zazhi. 2011; 21:239-241.

36. Wang Q, Zhang C, Walayat S, Chen HW, Wang Y. Association between cytokine gene polymorphisms and cervical cancer in a Chinese population. Eur J Obstet Gynecol Reprod Biol. 2011; 158:330-333.

37. Barbisan G, Perez LO, Contreras A, Golijow CD. TNFalpha and IL-10 promoter polymorphisms, HPV infection, and cervical cancer risk. Tumour Biol. 2012; 33:1549-1556.

38. Singhal P, Kumar A, Bharadwaj S, Hussain S, Bharadwaj M. Association of IL-10 GTC haplotype with serum level and HPV infection in the development of cervical carcinoma. Tumour Biol. 2015; 36:2287-2298.

39. Zidi S, Gazouani E, Stayoussef M, Mezlini A, Ahmed SK, Yacoubi-Loueslati B, Almawi WY. IL-10 gene promoter and intron polymorphisms as genetic biomarkers of cervical cancer susceptibility among Tunisians. Cytokine. 2015; 76:343-347.

40. Torres-Poveda K, Burguete-Garcia AI, Bahena-Roman M, Mendez-Martinez R, Zurita-Diaz MA, Lopez-Estrada G, Delgado-Romero K, Peralta-Zaragoza O, BermudezMorales VH, Cantu D, Garcia-Carranca A, Madrid-Marina V. Risk allelic load in Th2 and Th3 cytokines genes as biomarker of susceptibility to HPV-16 positive cervical cancer: a case control study. BMC Cancer. 2016; 16:330.

41. Zeng YY, Chen XY, Tian KG, Reng HY, Li ZR, Zhao Q. The correlation of interleukin-10 gene polymorphism and HPV infection and cervical lesions in Dongguan region (China). Journal of Clinical and Experimental Medicine. $2015 ; 14: 636-639$. 
42. Bai CY, Shi XY, He J, Xue J, Feng Y. Association between IL-10 genetic variations and cervical cancer susceptibility in a Chinese population. Genet Mol Res. 2016; 15.

43. Singh H, Jain M, Sachan R, Mittal B. Association of TNFA $(-308 \mathrm{G}>\mathrm{A})$ and IL-10 $(-819 \mathrm{C}>\mathrm{T})$ promoter polymorphisms with risk of cervical cancer. Int J Gynecol Cancer. 2009; 19:1190-1194.

44. Ivansson EL, Gustavsson IM, Magnusson JJ, Steiner LL, Magnusson PK, Erlich HA, Gyllensten UB. Variants of chemokine receptor 2 and interleukin 4 receptor, but not interleukin 10 or Fas ligand, increase risk of cervical cancer. Int J Cancer. 2007; 121:2451-2457.

45. Xiong XD, Lu SX, Zeng LQ, Chen MJ, Yang ZH, Luo XP, Liu XG. Relationship between IL-10 -592A > C promoter polymorphism and the susceptibility to cervical cancer (China). Zhongguo Yousheng Yu Yichuan Zazhi. 2010; 18:46-48.

46. Shekari M, Kordi-Tamandani DM, MalekZadeh K, Sobti RC, Karimi S, Suri V. Effect of anti-inflammatory (IL-4, IL10) cytokine genes in relation to risk of cervical carcinoma. Am J Clin Oncol. 2012; 35:514-519.

47. Shusterman A, Salyma Y, Nashef A, Soller M, Wilensky A, Mott R, Weiss EI, Houri-Haddad Y, Iraqi FA. Genotype is an important determinant factor of host susceptibility to periodontitis in the Collaborative Cross and inbred mouse populations. BMC Genet. 2013; 14:68.

48. Friedmann PS, Sanchez-Elsner T, Schnuch A. Genetic factors in susceptibility to contact sensitivity. Contact Dermat. 2015; 72:263-274.

49. Brockmann L, Giannou AD, Gagliani N, Huber S. Regulation of TH17 Cells and Associated Cytokines in Wound Healing, Tissue Regeneration, and Carcinogenesis. Int J Mol Sci. 2017; 18.
50. Gandolfi G, Ragazzi M, Frasoldati A, Piana S, Ciarrocchi A, Sancisi V. TERT promoter mutations are associated with distant metastases in papillary thyroid carcinoma. Eur $\mathrm{J}$ Endocrinol. 2015; 172:403-413.

51. Wu J, Huang Q, Meng D, Huang M, Li C, Qin T. A Functional rs353293 Polymorphism in the Promoter of miR-143/145 Is Associated with a Reduced Risk of Bladder Cancer. PLoS One. 2016; 11:e0159115.

52. Yu Z, Liu Q, Huang C, Wu M, Li G. The interleukin 10 $-819 \mathrm{C} / \mathrm{T}$ polymorphism and cancer risk: a HuGE review and meta-analysis of 73 studies including 15,942 cases and 22,336 controls. OMICS. 2013; 17:200-214.

53. Li XF, Yin XH, Cai JW, Wang MJ, Zeng YQ, Li M, Niu YM, Shen M. Significant association between lncRNA H19 polymorphisms and cancer susceptibility: a meta-analysis. Oncotarget. 2017; 8:45143-53. https://doi.org/10.18632/ oncotarget.16658.

54. Huedo-Medina TB, Sanchez-Meca J, Marin-Martinez F, Botella J. Assessing heterogeneity in meta-analysis: Q statistic or I2 index? Psychol Methods. 2006; 11:193-206.

55. Mantel N, Haenszel W. Statistical aspects of the analysis of data from retrospective studies of disease. J Natl Cancer Inst. 1959; 22:719-748.

56. DerSimonian R. Meta-analysis in the design and monitoring of clinical trials. Stat Med. 1996; 15:1237-48.

57. Egger M, Davey Smith G, Schneider M, Minder C. Bias in meta-analysis detected by a simple, graphical test. BMJ. 1997; 315:629-634.

58. Begg CB, Mazumdar M. Operating characteristics of a rank correlation test for publication bias. Biometrics. 1994; 50:1088-1101. 